\title{
Present Status of Endoscopic Submucosal Dissection for Non- Ampullary Duodenal Epithelial Tumors
}

\author{
Naomi Kakushima, Masao Yoshida, Yohei Yabuuchi, Noboru Kawata, Kohei Takizawa, Yoshihiro Kishida, Sayo Ito, Kenichiro Imai, \\ Kinichi Hotta, Hirotoshi Ishiwatari, Hiroyuki Matsubayashi and Hiroyuki Ono \\ Division of Endoscopy, Shizuoka Cancer Center, Shizuoka, Japan
}

Prediction of histology by endoscopic examination is important in the clinical management of non-ampullary duodenal epithelial tumors (NADETs), including adenoma and adenocarcinoma. The use of a simple scoring system based on the findings of white-light endoscopy or magnified endoscopy with narrow-band imaging is useful to differentiate between Vienna category 3 (C3) and C4/5 lesions. Less invasive endoscopic resection procedures, such as cold snare polypectomy, are quick to perform and convenient for small $(\leq 10 \mathrm{~mm})$ C3 lesions. Neoplasms with higher grade histology, such as C4/5 lesions, should be treated by endoscopic mucosal resection (EMR), endoscopic submucosal dissection (ESD), or surgery. Although EMR often requires piecemeal resection, the complication rate is acceptable. Excellent complete resection rates could be achieved by ESD; however, it remains a challenging method considering the high risk of complications. Shielding or closure of the ulcer after ESD is effective at decreasing the risk of delayed bleeding and perforation. Laparoscopic endoscopic cooperative surgery is an ideal treatment with a high rate of en bloc resection and a low rate of complications, although it is limited to high-volume centers. Patients with NADETs could benefit from a multidisciplinary approach to stratify the optimal treatment based on endoscopic diagnoses. Clin Endosc 2020;53:652-658

Key Words: Endoscopic mucosal resection; Endoscopic submucosal dissection; Laparoscopic endoscopic cooperative surgery; Nonampullary duodenal epithelial tumors

\section{INTRODUCTION}

Non-ampullary duodenal carcinoma (NADC) is a rare but serious cancer among small bowel cancers. Since the treatment outcomes for advanced NADC are not satisfactory, it is important to diagnose NADC at an early stage. Although familial adenomatous polyposis (FAP) and other hereditary diseases are well-known risk factors for NADC, the risk factors for sporadic cases have not been well clarified. Most sporadic NADC cases are incidentally found during screening

Received: September 16, 2019 Revised: November 3, 2019

Accepted: November 15, 2019

Correspondence: Naomi Kakushima

Division of Endoscopy, Shizuoka Cancer Center, 1007 Shimonagakubo, Nagaizumi, Suntogun, Shizuoka 411-8777, Japan

Tel: +81-55-989-5222, Fax: +81-55-989-5551, E-mail: n.kakushima@scchr.jp ORCID: https://orcid.org/0000-0002-9635-2099

cc This is an Open Access article distributed under the terms of the Creative Commons Attribution Non-Commercial License (http://creativecommons.org/ licenses/by-nc/3.0) which permits unrestricted non-commercial use, distribution, and reproduction in any medium, provided the original work is properly cited. or surveillance for other diseases or by symptoms in advanced cases. However, it is known that the adenoma-carcinoma sequence is observed in the duodenum as well as in the colorectum. Therefore, the diagnosis of superficial non-ampullary duodenal epithelial tumors (NADETs), including duodenal adenomas and NADCs, is important to manage treatment selection and to achieve better prognosis. This article presents an overview of endoscopic diagnostic and resection methods for superficial NADETs and aims to discuss the present role of endoscopic submucosal dissection (ESD) in the duodenum. The term "superficial" is used to represent lesions confined to the mucosa or submucosa.

\section{DIAGNOSIS FOR SUPERFICIAL NADETS (ADENOMA AND CARCINOMA)}

\section{Differentiation from non-neoplastic lesions}

To avoid unnecessary resection of benign duodenal lesions, 
differential diagnosis between non-tumorous lesions and NADETs is essential. One should be aware of the features of various non-neoplastic lesions. In fact, polypoid lesions observed in the duodenum may be a manifestation of duodenitis, ectopic gastric mucosa, foveolar metaplasia, hyperplastic polyp, or Brunner's hyperplasia. There is also a possibility of metastasis from tumors of other organs. Factors favoring the diagnosis of superficial NADETs are the presence of demarcation or a border in mucosal structures and the difference in color between the lesion and surrounding mucosa suggesting epithelial neoplastic changes. The presence of milky white mucosa or a white opaque substance, characteristic of NADETs, is also a helpful finding. Milky white mucosa is considered to be the result of accumulation of lipid droplets inside epithelial cells due to the overproduction of chylomicron in neoplastic tissues.

\section{Characteristics of superficial NADETs}

Regarding the characteristics of superficial NADETs, the relationship between endoscopic findings and histology was reported in a multicenter study. ${ }^{2}$ Most superficial NADETs were found in the second portion of the duodenum, with a 0 -I or 0-IIa macroscopic type. In terms of the color of lesions, most low-grade adenomas (Vienna classification category 3, C3) were isochromatic or white, ${ }^{3}$ whereas the proportion of red lesions increased among high-grade adenoma (C4) or intramucosal or submucosal invasive adenocarcinoma (C4 or C5). Pathologically, most superficial NADCs were of the differentiated type histology. ${ }^{2}$

\section{Diagnosis based on white-light endoscopy}

Previous studies have shown that the endoscopic findings suggestive of carcinoma included the presence of depression, redness, and uneven nodularity. ${ }^{2,4}$ Based on previous reports

Table 1. White-Light Scoring System to Differentiate between C3 and C4/5 Lesions

\begin{tabular}{|c|c|c|c|}
\hline \multirow{2}{*}{ Endoscopic finding } & \multicolumn{3}{|c|}{ Score } \\
\hline & 0 & 1 & 2 \\
\hline Lesion diameter & $<10 \mathrm{~mm}$ & $\geq 10 \mathrm{~mm}$ & \\
\hline Color & White & Isochromatic & Red \\
\hline Macroscopic type & $\begin{array}{c}\text { Is, Ip, IIa } \\
\text { without depression }\end{array}$ & Any type with depression or mixed type & \\
\hline Nodularity & Uniform & Heterogeneous or none & \\
\hline
\end{tabular}

A total score of 2 points or less indicates C3, 3 points or higher indicates C4/5.
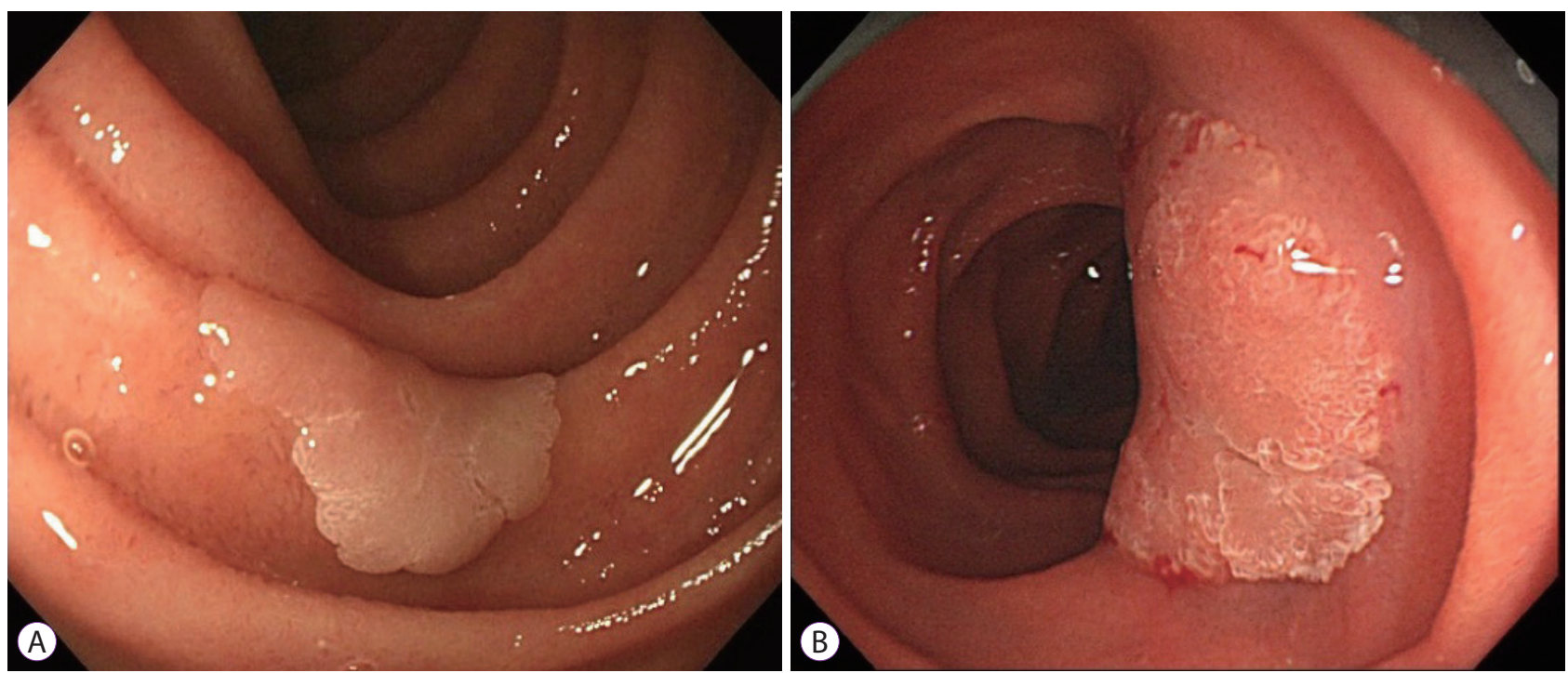

Fig. 1. Differentiation between $C 3$ and $C 4 / 5$ lesions using the white light scoring system. (A) A 12-mm-sized, white, slightly elevated lesion with lobulation. Size: $\geq 10$ $\mathrm{mm}(1)+$ color: white $(0)+$ lobulation: regular $(0)+$ type: 0 -lla $(0)=$ score 1. Pathology showed a low-grade adenoma (C3). (B) A 28-mm-sized isochromatic and partially reddish elevated lesion with rough surface and poor lobulation. Size: $\geq 10 \mathrm{~mm}(1)+$ color: red $(2)+$ lobulation: heterogenous or none $(1)+$ type: 0 -lla $(0)=$ score 4 . Pathology showed an intramucosal well differentiated adenocarcinoma (Cu). 
and our experience, we developed a white-light (WL) scoring system to diagnose C4/5 lesions (Table 1, Fig. 1). Using four endoscopic findings including lesion diameter, color, macroscopic type, and nodularity, the diagnosis of $\mathrm{C} 4 / 5$ by a total score of 3 points or more yielded an accuracy rate of $86 \%{ }^{4}$ The merit of using the WL scoring system is that it can be applied at any time during endoscopy screening without chromo-endoscopy, narrow-band imaging (NBI), or magnification.

\section{Diagnosis based on narrow-band imaging magnification}

Nowadays, NBI is often used for the diagnosis of esophageal, gastric, and colorectal lesions. Several studies have reported that an irregularity or disappearance of surface structure in the duodenum was indicative of carcinoma. ${ }^{1,5}$ Based on our experience with magnified endoscopy with NBI, we classified NBI findings into 4 patterns as per the combination of mucosal structure and vasculature (Fig. 2). The "dense or intra-structural vessels" pattern shows vasculature within the villi, irrespective of the size or shape of the villi. The "network" pattern shows regular arrangements of surface and vasculature pattern. The "white opaque substance" pattern shows whitish mucosa with no vasculature. The "disappeared-irregular" pattern shows obscure mucosal structure with irregular vessels (Fig. 2). When two or more of these patterns were observed within a lesion or when a "disappeared-irregular" pattern was observed, the diagnosis for $\mathrm{C} 4 / 5$ had an accuracy of $72 \%$ and moderate interobserver agreement. ${ }^{6}$ Although the classification of NBI patterns may be subjective and complicated, recognizing whether there is a uniform or multiple patterns within a lesion may be a simple approach to diagnose superficial NADETs. To make a differential diagnosis between C3 and C4/5, it is important to select the appropriate method of resection.

\section{TREATMENT SELECTION FOR SUPERFICIAL NADETS}

There are several resection methods available for superficial NADETs, spanning from the least invasive cold forceps pol-
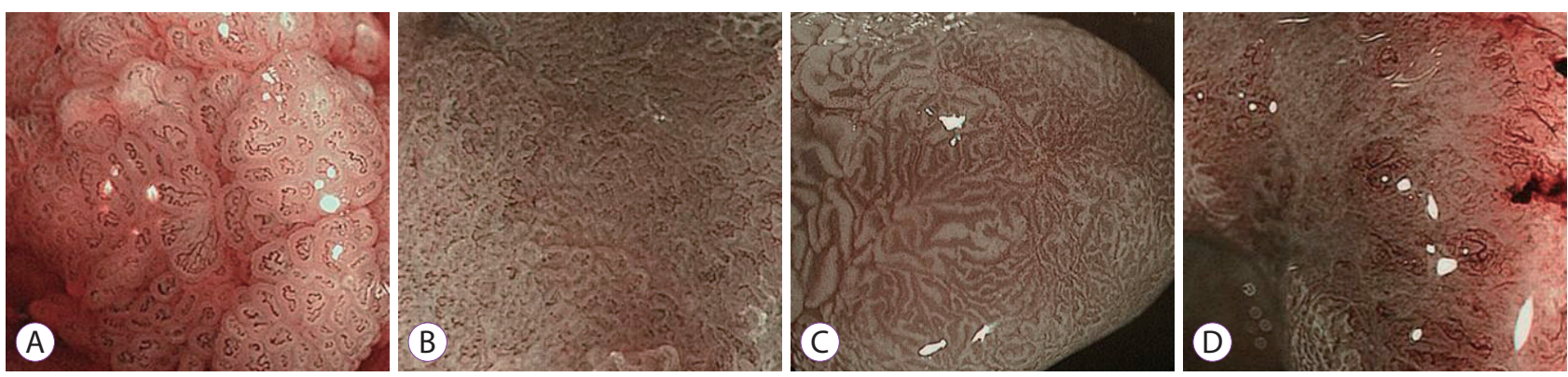

Fig. 2. Patterns of magnified endoscopy with narrow-band imaging of superficial non-ampullary duodenal epithelial tumors: (A) surface villous structure with intrastructural vessels, (B) surface tubular structure with network vessels (Network), (C) white opaque substance with no apparent vessels (WOS), (D) surface disappeared structure with irregular vessels (disappeared-irregular).

Table 2. Indication, Advantages and Disadvantages of Each Endoscopic Treatment Modality for Non-Ampullary Duodenal Epithelial Tumors

\begin{tabular}{|c|c|c|c|}
\hline Method & Advantages & Disadvantages & Recommended indication \\
\hline Cold snare polypectomy & $\begin{array}{l}\text { Fast } \\
\text { Easy } \\
\text { Less complication }\end{array}$ & $\begin{array}{l}\text { Incomplete resection of muscularis } \\
\text { mucosa } \\
\text { Indeterminate resection margin }\end{array}$ & $\mathrm{C} 3: \leq 10 \mathrm{~mm}$ \\
\hline $\begin{array}{l}\text { EMR (including underwater } \\
\text { EMR) }\end{array}$ & $\begin{array}{l}\text { Capable of removing } \\
\text { muscularis mucosa, not } \\
\text { so difficult }\end{array}$ & $\begin{array}{l}\text { Moderate risk of complication } \\
\text { Low en bloc rate for lesions } \geq 20 \mathrm{~mm}\end{array}$ & $\begin{array}{l}\text { C3: }>10 \mathrm{~mm} \\
\text { C4/5: } \leq 20 \mathrm{~mm} \text { with no findings of } \\
\text { SM invasion }\end{array}$ \\
\hline $\begin{array}{l}\text { Endoscopic submucosal } \\
\text { dissection }\end{array}$ & High en bloc rate & $\begin{array}{l}\text { High risk of complication } \\
\text { Technically demanding }\end{array}$ & $\begin{array}{l}\mathrm{C} 4 / 5: \leq 30 \mathrm{~mm} \text { with no findings of } \\
\mathrm{SM} \text { invasion }\end{array}$ \\
\hline $\begin{array}{l}\text { Laparoscopic endoscopic } \\
\text { collaborative surgery }\end{array}$ & $\begin{array}{l}\text { High en bloc rate } \\
\text { Less complication }\end{array}$ & $\begin{array}{l}\text { Technically demanding } \\
\text { Requires general surgery } \\
\text { No long-term data }\end{array}$ & $\begin{array}{l}\mathrm{C} 4 / 5: \leq 30 \mathrm{~mm} \text { with no extension } \\
\text { to periampullary area, no find- } \\
\text { ings of SM invasion }\end{array}$ \\
\hline
\end{tabular}

EMR, endoscopic mucosal resection; SM, submucosal. 
ypectomy to radical surgery such as pancreatoduodenectomy. Regarding duodenal adenocarcinoma, previous studies have shown no lymph node metastasis (LNM) for intra-mucosal (T1a) carcinoma, whereas submucosal invasive (T1b) adenocarcinomas had an LNM metastasis rate of around 5\%-42\% (TNM classification 8th edition, Union for International Cancer Control). ${ }^{7}$ Therefore, adenoma or clinical Tla carcinomas are suitable candidates for local resection. Surgery with adequate lymph node dissection should be applied to clinical T1b carcinoma (Table 2).

\section{Cold snare polypectomy for NADETs}

Cold snare polypectomy (CSP) is commonly performed for small colorectal polyps. Several studies on colonoscopy have reported that CSP is easy and quick to perform, applicable even for flat lesions, less likely to cause bleeding than hot snare polypectomy or endoscopic mucosal resection (EMR), and has a low risk of perforation. The utility of CSP for small sporadic NADETs has been reported in a small prospective study. ${ }^{8}$ Although data regarding the efficacy and safety of CSP for duodenal lesions are still lacking, CSP has been applied in patients with FAP with multiple polyps. A total of 126 duodenal polyps among 4 FAP patients were removed by CSP with no apparent delayed bleeding. ${ }^{9}$ Regarding the efficacy of CSP, an analysis based on colonic polyps sized $\leq 10 \mathrm{~mm}$ reported that polyp retrieval failure occurred in $7 \%$ of CSP cases. ${ }^{10}$ Histologically, unclear margins were observed in 36\% of CSP cases for which pathological diagnosis was possible. ${ }^{10}$ Another study on colonic polyps reported that only $2 \%$ of CSP samples included the submucosa. ${ }^{11}$ Therefore, there are still concerns about the application of CSP for high-grade adenomas or carcinomas that need resection including the submucosal tissue.

\section{Endoscopic mucosal resection for NADETs}

Regarding EMR for superficial NADETs, many case series have been reported since 1997 (Fig. 3). Among these reports, the en bloc resection rate varies with lesion size: for lesions smaller than $20 \mathrm{~mm}$, it is high at around $80 \%-90 \%$; however for lesions larger than $20 \mathrm{~mm}$, it decreases to nearly $30 \%-40 \%$. For lesions resected in a piecemeal fashion, re-treatment for local recurrence was reported in up to $37 \%$ of cases. Since most of the resected lesions were adenomas, recurrent lesions
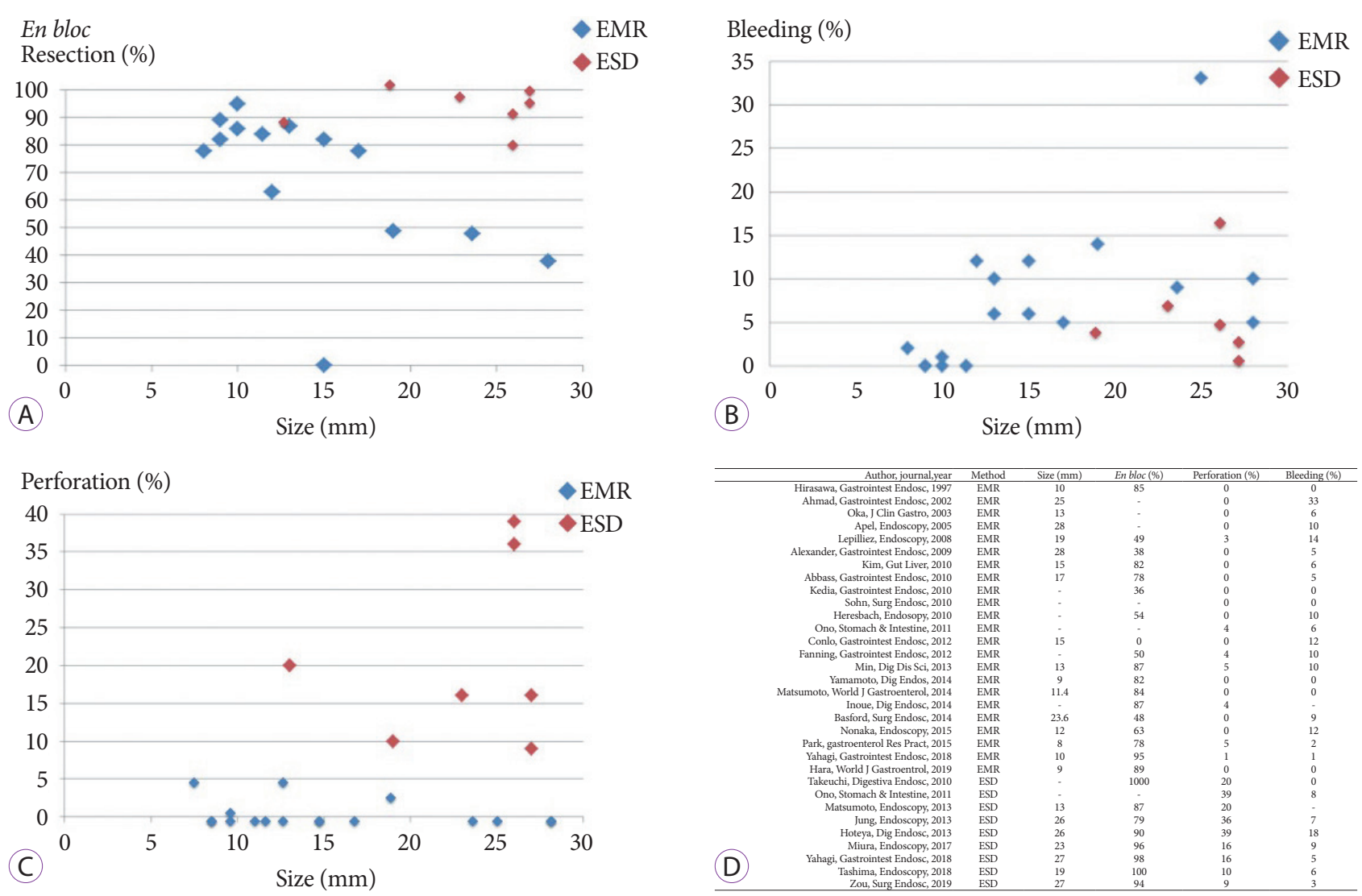

Fig. 3. Results of endoscopic mucosal resection (EMR) and endoscopic submucosal dissection (ESD) for superficial non-ampullary duodenal epithelial tumors according to size, en bloc resection rate, bleeding rate, and perforation rate. (A) En bloc resection rates of EMR and ESD. (B) Bleeding rates of EMR and ESD. (C) Perforation rates of EMR and ESD. (D) Studies included in the analysis. 
mostly involved adenomatous tissue and were treated by argon plasma coagulation or another EMR. Regarding the safety of duodenal EMR, bleeding occurred in about $5 \%-15 \%$ cases, the perforation rate was $0 \%-5 \%$, delayed perforation occurred in $0 \%-4 \%$ cases, and the rate of emergency surgery for either uncontrollable bleeding or perforation was $0 \%-5 \%$. Briefly, although the en bloc resection rate is low for lesions larger than $20 \mathrm{~mm}$, and piecemeal resection is often required for them, the safety profile for EMR is rather acceptable. Therefore, adenomas and small T1a carcinomas are considered suitable candidates for EMR

\section{Underwater endoscopic mucosal resection for NADETs}

Underwater EMR is a recently developed EMR technique for colorectal lesions and is also available for superficial NADETs. ${ }^{12}$ Immersion with normal saline reportedly facilitates snaring of the lesion via the floating effect. In addition, thermal injury to the muscle layer is expected to be lower due to the cooling effect. In combination, layer separation and thermal dissipation are thought to decrease the risk of early and delayed perforation. ${ }^{13}$ Although data from large-scale studies are not available, the usefulness of underwater EMR for complete resection and safety for adenomas $20 \mathrm{~mm}$ or smaller ${ }^{14}$ or for lesions with biopsy scars ${ }^{15}$ have been reported.

\section{Endoscopic submucosal dissection for NADETs}

ESD in the duodenum was approved in 2006 by the $\mathrm{Na}$ tional Health Insurance in Japan along with ESD for gastric carcinomas. It has been applied for lesions that are considered to require en bloc resection or for lesions that could not be removed by EMR, such as non-lifting lesions after injection. The results of duodenal ESD from studies including 10 or more cases are shown in Fig. 3. In contrast to EMR, a high proportion of adenocarcinomas were included in those studies and the median size was larger, but the rate of en bloc resection was over $90 \%$ among the latest reports. Although the follow-up period was short, no local recurrence was reported after a successful ESD. However, the complication rates of ESD were very high. The bleeding rate was up to $18 \%$, the perforation rate was around $9 \%-39 \%$, and the delayed perforation rate was up to $9 \%$, and the emergency surgery rate was up to $14 \%$.

\section{Complications of duodenal endoscopic submucosal dissection}

Delayed perforation is a distinctive complication of duodenal ESD. Even after a successful ESD without intra-operative perforation, a complete defect may occur the following day. Delayed perforation is a serious complication that may cause potentially fatal peritonitis, requiring emergency open surgery for performing adequate peritoneal lavage to counter the leakage of bile and pancreatic juices. Lesions located anally to the Vater's papilla or piecemeal resection with too much coagulation have been reported as possible risk factors. ${ }^{16}$

Delayed bleeding is another major complication of duodenal ESD. A previous study reported that among patient-, lesion-, and treatment-related factors, only endoscopic closure of the ulcer after duodenal ESD was an effective measure to reduce the risk of delayed bleeding. ${ }^{17}$ Therefore, closure of the ulcer after duodenal ESD is considered an effective way to decrease the incidence of both delayed bleeding and perforation. Several methods of closure have been reported, including shielding with polyglycolic acid (PGA) sheets and fibrin glue ${ }^{18,19}$; closure with a combination of clips and endoloop or a combination of clips and string ${ }^{20}$; and closure using over-thescope-clips (OTSCs). ${ }^{21}$ Shielding with a PGA sheet with fibrin glue is expected to remain on the ulcer bed for at least a week. Closure with a combination of clips and endoloop or string may be easier to perform and offer a stronger closure than that obtained using only clips and may prevent early dislocations of the clips. OTSCs are large and characterized by their strong grasping and holding force; they can remain in place for several months.

\section{Laparoscopic endoscopic cooperative surgery for NADETs}

The latest endoscopic treatment is laparoscopic-assisted endoscopic full-thickness resection or laparoscopic endoscopic cooperative surgery (LECS). ${ }^{22}$ There are several variations of these methods; (1) full thickness marking performed by endoscopy followed by laparoscopic local resection, (2) partial or circumferential full-thickness resection performed by endoscopy followed by laparoscopic local resection, and (3) a duodenal ESD followed by laparoscopic suture of the ESD ulcer. For NADCs, the first two methods may have a risk of cancer dissemination because the lumen is exposed to the peritoneal cavity, thus, nowadays it is applied to small neuroendocrine tumors. The third method, duodenal ESD followed by laparoscopic reinforcing with seromuscular suturing (D-LECS), is gradually gaining acceptance for mucosal adenocarcinoma; however, its use is still limited to high-volume centers. It is an ideal treatment that ensures necessary and sufficient resection of the lesion and provides a preventive measure to decrease the risk of delayed complications by suturing the ulcer. The merits of D-LECS are that for $100 \%$ of en bloc cases, R0 resection can be theoretically achieved with no major complications. Promising results have been reported for NADETs sized approximately $30 \mathrm{~mm}$ in diameter and located at least $10 \mathrm{~mm}$ away from the Vater's papilla. ${ }^{22}$ 
In contrast, the lesions located near the Vater's papilla or lesions larger than $40 \mathrm{~mm}$ are not candidates because of the risk of post-operative stricture and pancreatic fluid fistula. Moreover, it is necessary to exclude the possibility of $\mathrm{T} 1 \mathrm{~b}$ preoperatively, since additional surgery after an incomplete LECS would be difficult because of adhesion and alteration of anatomy and lymphatic flow.

\section{Piecemeal or en bloc?}

An important issue regarding local resection of superficial NADETs is the necessity of en bloc or piecemeal resection. This issue has been widely discussed in other areas of the gastrointestinal tract, such as the esophagus, stomach, and colorectum. In these areas, en bloc resection is an important factor for treating carcinoma, because the rate of en bloc resection is inversely proportional to the local recurrence rate. In the duodenum, the majority of previous EMR studies focused on adenomas, and although recurrence rates were higher with piecemeal resection, local recurrence was mostly controlled by another endoscopic treatment. Until now, there have been no reports on the disease-free survival of patients who underwent en bloc or piecemeal resection for superficial NADCs. In addition, the incidence of $\mathrm{Tlb}$ carcinoma is extremely low in the duodenum. A method that provides en bloc with R0 resection is an ideal treatment for Tla carcinoma. However, based on the high incidence of complications with ESD in the duodenum, EMR or local surgical resection should also be considered for the treatment of Tla carcinoma.

\section{Trends of treatment selection}

A retrospective multicenter study showed the chronological trend of treatment methods for superficial NADETs over a 23-year period in Japan. ${ }^{23}$ In the recent 5 years (2012 to 2016), 900 cases were treated, which is nearly twice as that treated in the previous 18 years (497 cases, 1993 to 2011). Although the ratio of EMR (57\%) did not change, the rate of ESD decreased from $41 \%$ to $27 \%$, and newer resection methods such as CSP or underwater EMR emerged to account for 10\% of all methods. ${ }^{23}$ This result shows that duodenal ESD is not yet widely accepted in Japan, and many endoscopists would prefer less invasive procedures such as EMR, CSP, and underwater EMR. Treatment should be selected according to the preoperative diagnosis of malignant potential, size, and location of the tumor, skill of the surgeon, and the institution. To resect small $\mathrm{C} 3$ or C4 lesions by less invasive methods such as CSP or underwater EMR before they progress to large $\mathrm{C} 4 / 5$ lesions may also be an acceptable strategy. Patients with superficial NADETs could benefit from a multidisciplinary approach to stratify the optimal treatment based on endoscopic diagnoses.

\section{CONCLUSIONS}

Without a doubt, ESD ensures a high en bloc resection rate and has been widely accepted for carcinomas in the esophagus, stomach, and colorectum because the associated complication rates in these areas are considered acceptable. Even in the colorectum, delayed perforation is rare at a rate of $0.1 \%-0.4 \%{ }^{24}$ However, in the duodenum, the complication rate is notably high compared to that in any other area in the gastrointestinal tract. The selected treatment should have a balance in terms of efficacy and safety. The high complication rate of duodenal ESD limits the clinical applicability of endoscopic en bloc resection in the duodenum. At present, this calls for caution over the indiscriminate use of ESD for the resection of duodenal lesions.

\section{Conflicts of Interest \\ The authors have no financial conflicts of interest.

\author{
Author Contributions \\ Conceptualization: Naomi Kakushima \\ Data curation: NKak \\ Formal analysis: NKak \\ Investigation: NKak \\ Methodology: NKak \\ Project administration: Masao Yoshida, Yohei Yabuuchi, Noboru Kawata, \\ Kohei Takizawa, Hiroyuki Ono \\ Supervision: Sayo Ito, Kenichiro Imai, Kinichi Hotta, Hirotoshi Ishiwatari, \\ Hiroyuki Matsubayashi \\ Validation: MY, YY, KT, NKaw, Yoshihiro Kishida, SI, KI, HI, HM, HO \\ Writing-original draft: NKak \\ Writing-review\&editing: MY, YY, NKaw, KT, YK, SI, KI, KH, HI, HM, \\ $\mathrm{HO}$
}

\section{ORCID}

Masao Yoshida: https://orcid.org/0000-0001-7272-0187 Yohei Yabuuchi: https://orcid.org/0000-0003-0491-2579

Noboru Kawata: https://orcid.org/0000-0002-4001-017X

Kohei Takizawa: https://orcid.org/0000-0002-7702-0427

Yoshihiro Kishida: https://orcid.org/0000-0002-5068-6990

Sayo Ito: https://orcid.org/0000-0003-0916-5445

Kenichiro Imai: https://orcid.org/0000-0002-9257-5842

Kinichi Hotta: https://orcid.org/0000-0001-5608-0968

Hirotoshi Ishiwatari: https://orcid.org/0000-0002-6719-4466

Hiroyuki Matsubayashi: https://orcid.org/0000-0002-7050-2351

Hiroyuki Ono: https://orcid.org/0000-0002-8215-1720

\section{REFERENCES}

1. Yoshimura N, Goda K, Tajiri H, Ikegami M, Nakayoshi T, Kaise M. Endoscopic features of nonampullary duodenal tumors with narrow-band imaging. Hepatogastroenterology 2010;57:462-467.

2. Goda K, Kikuchi D, Yamamoto Y, et al. Endoscopic diagnosis of superficial non-ampullary duodenal epithelial tumors in Japan: multicenter case series. Dig Endosc 2014;26 Suppl 2:23-29.

3. Dixon MF. Gastrointestinal epithelial neoplasia: Vienna revisited. Gut 
2002;51:130-131.

4. Kakushima N, Yoshida M, Iwai T, et al. A simple endoscopic scoring system to differentiate between duodenal adenoma and carcinoma. Endosc Int Open 2017;5:E763-E768.

5. Kikuchi D, Hoteya S, Iizuka T, Kimura R, Kaise M. Diagnostic algorithm of magnifying endoscopy with narrow band imaging for superficial non-ampullary duodenal epithelial tumors. Dig Endosc 2014;26 Suppl 2:16-22.

6. Kakushima N, Yoshida M, Yamaguchi Y, et al. Magnified endoscopy with narrow-band imaging for the differential diagnosis of superficial non-ampullary duodenal epithelial tumors. Scand J Gastroenterol 2019;54:128-134

7. Kakushima N, Kanemoto H, Tanaka M, Takizawa K, Ono H. Treatment for superficial non-ampullary duodenal epithelial tumors. World J Gastroenterol 2014;20:12501-12508.

8. Maruoka D, Matsumura T, Kasamatsu S, et al. Cold polypectomy for duodenal adenomas: a prospective clinical trial. Endoscopy 2017;49:776783.

9. Hamada K, Takeuchi Y, Ishikawa H, et al. Feasibility of cold snare polypectomy for multiple duodenal adenomas in patients with familial adenomatous polyposis: a pilot study. Dig Dis Sci 2016;61:2755-2759.

10. Ichihara S, Uraoka T, Oka S. Challenges associated with the pathological diagnosis of colorectal tumors less than $10 \mathrm{~mm}$ in size. Dig Endosc 2018;30 Suppl 1:41-44.

11. Lee CK, Shim JJ, Jang JY. Cold snare polypectomy vs. cold forceps polypectomy using double-biopsy technique for removal of diminutive colorectal polyps: a prospective randomized study. Am J Gastroenterol 2013;108:1593-1600.

12. Binmoeller KF, Shah JN, Bhat YM, Kane SD. "Underwater" EMR of sporadic laterally spreading nonampullary duodenal adenomas (with video). Gastrointest Endosc 2013;78:496-502.

13. Binmoeller KF. Underwater EMR without submucosal injection: is less more? Gastrointest Endosc 2019;89:1117-1119.

14. Yamasaki Y, Uedo N, Takeuchi Y, et al. Underwater endoscopic mucosal resection for superficial nonampullary duodenal adenomas. Endoscopy 2018;50:154-158.

15. Kato M, Tsujii Y, Takehara T. Underwater endoscopic mucosal resection of a duodenal adenoma with biopsy scars. Dig Endosc 2018;30:405-406.

16. Inoue $\mathrm{T}$, Uedo $\mathrm{N}$, Yamashina $\mathrm{T}$, et al. Delayed perforation: a hazardous complication of endoscopic resection for non-ampullary duodenal neoplasm. Dig Endosc 2014;26:220-227.

17. Hoteya S, Kaise M, Iizuka T, et al. Delayed bleeding after endoscopic submucosal dissection for non-ampullary superficial duodenal neoplasias might be prevented by prophylactic endoscopic closure: analysis of risk factors. Dig Endosc 2015;27:323-330.

18. Doyama H, Tominaga K, Yoshida N, Takemura K, Yamada S. Endoscopic tissue shielding with polyglycolic acid sheets, fibrin glue and clips to prevent delayed perforation after duodenal endoscopic resection. Dig Endosc 2014;26 Suppl 2:41-45.

19. Takimoto K, Imai Y, Matsuyama K. Endoscopic tissue shielding method with polyglycolic acid sheets and fibrin glue to prevent delayed perforation after duodenal endoscopic submucosal dissection. Dig Endosc 2014;26 Suppl 2:46-49.

20. Yahagi N, Nishizawa T, Akimoto T, Ochiai Y, Goto O. New endoscopic suturing method: string clip suturing method. Gastrointest Endosc 2016;84:1064-1065

21. Mori H, Shintaro F, Kobara H, et al. Successful closing of duodenal ulcer after endoscopic submucosal dissection with over-the-scope clip to prevent delayed perforation. Dig Endosc 2013;25:459-461.

22. Toma H, Haraguchi K, Fujii K, Kobarai T, Hirota I, Eguchi T. Laparoscopic and endoscopic cooperative surgery for non-ampullary duodenal epithelial neoplasms. Mini-invasive Surgery 2018;2:21.

23. Ono $\mathrm{H}$, Kaise M, Nonaka S, et al. [Clinical issues of duodenal endoscopic treatment]. Stomach and Intestine 2016;51:1585-1592.

24. Tanaka S, Kashida H, Saito Y, et al. JGES guidelines for colorectal endoscopic submucosal dissection/endoscopic mucosal resection. Dig Endosc 2015;27:417-434 